\title{
Effect of Reducing Nitrogen and Applying Organic Fertilizer on Nitrogen Use Efficiency and Rice Yield in Red Soil Regions of the Southern China
}

\author{
Qihong Tu' ${ }^{1}$ Zhenjiang Zhang ${ }^{1}$, Min Liu ${ }^{2}$ \\ ${ }^{1}$ Key Laboratory of Digital Land and Resources, East China University of Technology, Nanchang, China \\ ${ }^{2}$ Agricultural Technology Extension Station of Fengcheng City, Yichun, China
}

Email address:

qihtu@163.com (Qihong Tu)

\section{To cite this article:}

Qihong Tu, Zhenjiang Zhang, Min Liu. Effect of Reducing Nitrogen and Applying Organic Fertilizer on Nitrogen Use Efficiency and Rice Yield in Red Soil Regions of the Southern China. Journal of Energy, Environmental \& Chemical Engineering. Vol. 6, No. 1, 2021, pp. 10-15. doi: $10.11648 /$ j.jeece.20210601.12

Received: November 26, 2020; Accepted: December 22, 2020; Published: January 12, 2021

\begin{abstract}
To explore the amount of reducing $\mathrm{N}$ fertilizer, a 2-year field experiment was conducted to investigate the effects of reducing $\mathrm{N}$ fertilizer and applying organic fertilizer on nitrogen use efficiency (NUE) and rice yield in red soil regions of the Southern China. On the basis of applying $4500 \mathrm{~kg} / \mathrm{ha}$ organic fertilizer and local custom fertilization with $204 \mathrm{~kg} / \mathrm{ha}$ urea application, five treatments including no nitrogen fertilization (CK), local customary nitrogen application (N100), and nitrogen reduction of $10 \%(\mathrm{~N} 90), 20 \%(\mathrm{~N} 80)$, and $30 \%$ (N70) were conducted. The results showed that nitrogen agronomic efficiency (NAE), nitrogen recovery efficiency (NRE), nitrogen physiological efficiency (NPE) and nitrogen partial factor productivity (NPFP) of N90 treatment were significantly higher than those of other treatments, and the yield was as high as $9.33 \mathrm{t} / \mathrm{ha}$, which showed a significant differences compared with $\mathrm{CK}$ and N100. The output value, benefit, and benefit-cost ratio of N90 were significantly higher than those of $\mathrm{N} 100$, which increased by $6.38 \%, 6.42 \%, 8.35 \%$, and $8.20 \%$, respectively. In addition, while applying the same amount of organic fertilizer, the rate of nitrogen reduction has little effect on the soil organic matter content, meaning that N90 can achieve high NUE and high yield in rice. It is good to provide the theory basis for fertilizer decision-making in practice.
\end{abstract}

Keywords: Red Soil Regions of the Southern China, Reduced Nitrogen Application, Organic Fertilizer Application, Nitrogen Use Efficiency

\section{Introduction}

Study has suggested that adequate fertilization is important for plant growth healthily with high crop yield [18]. With the improvement of agricultural intensification in China, the amount of chemical fertilizers has increased significantly. Grain production is characterized by high input and high yield in China, the amount of nitrogen fertilizer accounts for $30 \%$ of the world's nitrogen use, and the nitrogen fertilizer used in rice production accounts for $37 \%$ of the world's nitrogen fertilizer, the amount nitrogen fertilizer in China is about $75 \%$ higher than the average amount of that in the world [13]. Zhang summarized the results of 1333 field trials in China's major grain production areas in recent years, and found that the nitrogen use efficiency of major grain crops was $10.8 \%-40.5 \%$ in China, with an average of $27.5 \%$, far lower than the world level of $40 \%-60 \%[5,22]$. The serious loss of soil nitrogen and the low nitrogen use efficiency are one of the important problems that restrict the development of high-yield, efficient and high-quality agriculture in China. How to improve the soil nitrogen supply capacity, reduce the loss of nitrogen nutrients, and enhance the nitrogen use efficiency is an important issue that needs to be solved urgently. Excessive nitrogen fertilizer input in paddy field will result in not only acidification of the soil and reducing nitrogen use efficiency, but also a series of environmental problems [11, 14]. Meanwhile, the organic fertilizer application has gradually decreased. In this regard, the combination of organic and inorganic fertilizers may be a possible remedy to increase yields and avoid environmental pollution, especially in rice fields. The application of organic 
fertilizer can greatly improve the negative impact of single application of chemical fertilizers on the soil and the environment. It has been shown that single application of organic fertilizer or combined application of chemical fertilizers can effectively increase soil organic matter content, soil enzyme activity and crop yields $[8,22]$. Relevant research proves that the combined application of organic and chemical fertilizers is beneficial to improve the crop nitrogen use efficiency $[1,12]$. Results from different studies revealed that continuous application of farmyard manure and green manure improved the soil organic carbon under different soils and cropping systems, therefore any nutrient management practice that can improve soil organic matter which sustaining crop productivity and reduce the amount of chemical fertilizers, use efficiency of agricultural waste resources and ease the pressure on the environment $[3,21]$.

In order to improve rice yield and nutrient use efficiency, many experiments have been conducted on paddy fields during the past decades, which most studies focusing on the effects of single inorganic fertilizer or combined organic fertilizer on rice production or NUE, but the effect of reducing $\mathrm{N}$ fertilizer and applying of organic fertilizer on nitrogen use efficiency and rice yield was rarely reported, especially in red soil regions of the Southern China. Therefore, we conducted the experiment (1) to comprehensively evaluate the effect of different reducing $\mathrm{N}$ fertilizer ratio on rice yield and NUE, compared to local customary nitrogen application (N100), (2) to investigate how the yield components varies with the different reducing $\mathrm{N}$ fertilizer ratio, and (3) to determine the ratio reducing $\mathrm{N}$ fertilizer when applying adequate organic fertilizer.

\section{Materials and Methods}

\subsection{Experimental Site}

The experiments were carried out at the agricultural experiment station $\left(115^{\circ} 25^{\prime} \mathrm{E}, \mathrm{N} 27^{\circ} 42^{\prime} \mathrm{N}\right)$, Rongtang Town of Fengcheng, Jiangxi Province in China during the 2017-2018 rice-growing season. The experimental site was situated in a subtropical humid region, with an average annual rainfall of 1,500 $\mathrm{mm}$. Average annual sunshine was $1935.7 \mathrm{~h}$, average annual temperature was $15.3-17.7^{\circ} \mathrm{C}$, maximum average humidity was $81 \%$.

Pre-experiment analysis showed that paddy field soil was medium loam. The basic physical and chemical properties of the soil are shown in Table 1.

Table 1. Basic properties of top soil $(0-20 \mathrm{~cm})$ tested.

\begin{tabular}{lllll}
\hline Organic matter (g/kg) & $\mathbf{p H}$ & Hydrolyze N (mg/kg) & Available P $(\mathbf{m g} / \mathbf{k g})$ & Available K $(\mathbf{m g} / \mathbf{k g})$ \\
\hline 46.00 & 5.01 & 225.10 & 26.02 & 135.50 \\
\hline
\end{tabular}

\subsection{Experimental Design}

Paddy rice (Zhuliangyou 718) was grown in completely randomized blocks with plot size of $126 \mathrm{~m}^{2}$, the fertilization treatments were designed as follows: no nitrogen fertilization (CK), local customary nitrogen application (N100), and nitrogen reduction of $10 \%(\mathrm{~N} 90), 20 \%(\mathrm{~N} 80)$, and $30 \%(\mathrm{~N} 70)$, on the basis of applying $4500 \mathrm{~kg} / \mathrm{ha}$ organic fertilizer and local custom fertilization with $94 \mathrm{~kg} / \mathrm{ha}$ nitrogen fertilizer. There were four replications which was arranged in a randomized block design in our field experiment. Transplanting was conducted at a space of $0.25 \mathrm{~m} \times 0.14 \mathrm{~m}$ with two seedlings per hill. Other managements, such as irrigation and insects followed thelocal high-yielding practice. The details of experimental design were listed in Table 2. Sampling and Laboratory Procedures

Table 2. Fertilization amount under different nitrogen reduction treatments.

\begin{tabular}{|c|c|c|c|c|}
\hline Treatment & Urea (kg/ha) & Kcl (kg/ha) & Calcium magnesium phosphate (kg/ha) & Organic fertilizer (kg/ha) \\
\hline $\mathrm{CK}$ & 0 & 87 & 300 & 4500 \\
\hline N100 & 204 & 87 & 300 & 4500 \\
\hline N90 & 169.5 & 87 & 300 & 4500 \\
\hline N80 & 133.5 & 87 & 300 & 4500 \\
\hline N70 & 97.5 & 87 & 300 & 4500 \\
\hline
\end{tabular}

The test fertilizers are urea $(\mathrm{N} 46 \%)$, superphosphate $\left(\mathrm{P}_{2} \mathrm{O}_{5} 12 \%\right)$, potassium chloride $\left(\mathrm{K}_{2} \mathrm{O} 60 \%\right)$; the organic fertilizer $(\mathrm{N} 1.57 \%$, organic matter $>45 \%)$ produced by Jiujiang Lilai Biotechnology company.

We selected $5 \mathrm{~m}^{2}$ areas in the middle of each plot to determine grain yields at harvest. Yields were adjusted to $14 \%$ moisture content fresh weight. At maturity, we counted the panicle numbers for $4 \mathrm{~m}^{2}$ areas ( 30 hills), and the 12 hills of each treatment were divided into their above-ground parts to determine the total dry weights and yield formations.
Rice plants were dried at $105^{\circ} \mathrm{C}$ for $30 \mathrm{~min}$ in the oven and then at $85^{\circ} \mathrm{C}$ to get a constant weight then digested with $\mathrm{H}_{2} \mathrm{SO}_{4}-\mathrm{H}_{2} \mathrm{O}_{2}$ at $265^{\circ} \mathrm{C}$. An Autoanalyser 3 Digital Colourmeter (Bran+Luebbe Inc., Norderstedt, Germany) was used to determine the total $\mathrm{N}$ concentration.

Some indicators were calculated as given in Eqs. (1)-(5):

Total nitrogen accumulation $(\mathrm{kg} / \mathrm{ha})=$ aboveground biomass per unit area $\times$ plant nitrogen content

Nitrogen recovery efficiency $=\frac{\text { nitrogen absorption of plants in nitrogen application plot-nitrogen absorption of plants in blank plot }}{\text { nitrogen application amount }} \times 100 \%$ 


$$
\text { Nitrogen agronomic efficiency }(\mathrm{kg} / \mathrm{kg})=\frac{\text { grain yield in nitrogen application plot-grain yield in blank plot }}{\text { nitrogen application amount }}
$$

Nitrogen physiological efficiency $(\mathrm{kg} / \mathrm{kg})=\frac{\text { Grain yield in nitrogen application plot-grain yield in blank plot }}{\text { Nitrogen uptake of plants in nitrogen application plot-Nitrogen uptake of plants in blank plot }}$

Nitrogen partial factor productivity $(\mathrm{kg} / \mathrm{kg})=\frac{\text { yield in nitrogen application plot }}{\text { nitrogen fertilizer application amount }}$

\subsection{Data Analysis}

Statistical evaluation of the data was performed by SPSS Statistics 25.0 (SPSS Armonk, NY: IBM Corp; 2019). The data were analyzed first by a one-way ANOVA, followed by Duncan's test if a significant difference was determined. Data are shown as mean \pm standard error $(n=4)$. All figures were generated with Micro Office Excel 2013. The differences between treatments are compared according to the least significant difference test (at a probability level of 5\%).

\section{Results}

\subsection{Rice Yield and Yield Components}

Date for rice yield and yield components under different treatments were presented in Table 3. Except for 1,000-grain weight, the panicle number plant ${ }^{-1}$, the number of spikelets panicle $^{-1}$, the seed setting rate and the actual yield of the CK treatment were significantly lower than those of other treatments. Thus it can be seen that nitrogen fertilizer significantly affects rice yield and yield components.

Significant difference was observed in the panicle number plant-1 among all the treatments, it was same with the number of spikeletspanicle-1 excepting for N100 and N70. Rice yield and yield components (excepting for 1,000-grain weight) of N90 were observed significantly higher than other treatment, and theoretical yield was presented as the order: N90 $>$ N800 $>$ $\mathrm{N} 100>\mathrm{N} 70>\mathrm{CK}$, the actual yield was presented as the order: $\mathrm{N} 90>\mathrm{N} 100>\mathrm{N} 80>\mathrm{N} 70>\mathrm{CK}$. The theoretical yield and actual yield of N90 treatment were $26.38 \%$ and $6.39 \%$ significantly higher than N100, respectively. In addition, we can find a surprising that there were no differences for 1,000-grain weight among the all treatments, which indicated that 1,000-grain weight is an inherent attribute of the rice variety.

Table 3. Effects of different treatments on rice yield and yield components.

\begin{tabular}{|c|c|c|c|c|c|c|}
\hline Treatment & Panicles $10^{4} /$ ha & Spikelets per panicle & $\begin{array}{l}\text { Seed setting rate } \\
(\%)\end{array}$ & $\begin{array}{l}\text { 1,000-grain } \\
\text { weight (g) }\end{array}$ & $\begin{array}{l}\text { Theoretical yield } \\
\text { (t/ha) }\end{array}$ & Actual yield (t/ha) \\
\hline CK & $268.50 \pm 1.39 \mathrm{e}$ & $83.90 \pm 0.26 \mathrm{~d}$ & $82.03 \pm 0.19 \mathrm{c}$ & $23.02 \pm 0.15 \mathrm{~b}$ & $5.19 \pm 0.08 \mathrm{~d}$ & $6.39 \pm 0.04 \mathrm{~d}$ \\
\hline N100 & $390.00 \pm 0.63 \mathrm{a}$ & $96.10 \pm 0.16 \mathrm{c}$ & $93.39 \pm 0.21 \mathrm{a}$ & $23.66 \pm 0.21 \mathrm{ab}$ & $8.87 \pm 0.12 b$ & $8.77 \pm 0.06 \mathrm{~b}$ \\
\hline N90 & $373.50 \pm 1.82 \mathrm{~b}$ & $125.60 \pm 0.31 \mathrm{~b}$ & $91.55 \pm 0.26 \mathrm{~b}$ & $23.89 \pm 0.16 \mathrm{ab}$ & $11.21 \pm 0.12 \mathrm{a}$ & $9.33 \pm 0.16 \mathrm{a}$ \\
\hline N80 & $345.00 \pm 0.55 \mathrm{c}$ & $131.90 \pm 0.10 \mathrm{a}$ & $94.15 \pm 0.08 \mathrm{a}$ & $23.76 \pm 0.17 \mathrm{ab}$ & $10.81 \pm 0.14 \mathrm{a}$ & $8.22 \pm 0.03 \mathrm{c}$ \\
\hline N70 & $337.50 \pm 0.33 \mathrm{~d}$ & $97.01 \pm 0.06 \mathrm{c}$ & $93.90 \pm 0.17 \mathrm{a}$ & $24.60 \pm 0.31 \mathrm{a}$ & $8.05 \pm 0.05 \mathrm{c}$ & $7.90 \pm 0.13 \mathrm{c}$ \\
\hline
\end{tabular}

Within treatment, means followed by different letters are significantly different according to LSD ( $\mathrm{p} \leq 0.05)$.

\subsection{Nitrogen Efficiency in Rice}

As shown in Table 4, nitrogen agronomic efficiency of N90 was significantly higher than other treatments, which is $36.98 \%, 43.23 \%$ and $51.57 \%$ more than N100, N80 and N70, respectively. It was same with nitrogen recovery efficiency but except for N100. Nitrogen physiological efficiency of N90 was the highest and there was significant difference compared with N100. Nitrogen partial factor productivity showed an upward trend gradually with the increasing of the nitrogen fertilizer reduction, it was observed that N70 was significantly higher than other treatments, which were $28.28 \%, 8.92 \%$ and $9.93 \%$ more than N100, N90 and N80 treatments, respectively. The results of the study showed that reducing the nitrogen fertilizer application rate by $10 \%$ can improve the nitrogen efficiency in rice, it is consistent with the research of Liu [9].

Table 4. Effects of different treatments on nitrogen use efficiency.

\begin{tabular}{llll}
\hline Treatment & NAE (kg/kg) & NRE (\%) & NPE (kg/kg) \\
\hline N100 & $14.44 \pm 0.21 \mathrm{bc}$ & $33.64 \pm 1.42 \mathrm{a}$ & $43.11 \pm 1.98 \mathrm{~b}$ \\
N90 & $19.78 \pm 1.06 \mathrm{a}$ & $34.76 \pm 1.92 \mathrm{a}$ & $57.28 \pm 4.55 \mathrm{a}$ \\
N80 & $13.81 \pm 0.26 \mathrm{c}$ & $26.75 \pm 1.77 \mathrm{~b}$ & $53.32 \pm 0.36 \mathrm{c}$ \\
N70 & $13.05 \pm 1.42 \mathrm{c}$ & $24.53 \pm 1.76 \mathrm{~b}$ & $51.99 \pm 3.05 \mathrm{ab}$ \\
\hline
\end{tabular}

Within treatment, means followed by different letters are significantly different according to LSD ( $\mathrm{p} \leq 0.05)$. Nitrogen agronomy efficiency (NAE), Nitrogen recovery efficiency (NRE), Nitrogen physiological efficiency (NPE), Nitrogen partial factor productivity (NPEP).

\subsection{Economic Benefit of Rice Production}

Date for yield, output value, fertilizer cost, benefit and benefit-cost ratio were presented in Table 5. All indicators of treatment N90 (except for fertilizer cost) were significantly higher than that of other treatments. Compared with N100, yield, output value, benefit and benefit-cost ratio of N90 showed significant differences, increased by $6.38 \%, 6.42 \%$, $8.35 \%$ and $8.20 \%$, respectively. In addition, these indicators showed the following rules: N90 $>$ N100 $>$ N80 $>$ N70. 
Considering synthetically these economic indicators such as fertilizer cost, output value, benefit and benefit-cost ratio, it was not difficult to find that N90 was the most suitable treatment to recommend. It can not only further control and reduce fertilizer costs, but also achieve higher output value and benefit-cost ratio.

Table 5. Effects of different treatments on benefit of rice production.

\begin{tabular}{llllll}
\hline Treatments & Yield (t/ha) & $\begin{array}{l}\text { Output value } \\
\text { (RMB/ha) }\end{array}$ & $\begin{array}{l}\text { Chemical fertilizer cost } \\
\text { (RMB/ha) }\end{array}$ & $\begin{array}{l}\text { Organic fertilizer } \\
\text { cost (RMB/ha) }\end{array}$ & Benefit (RMB/ha) \\
\hline N100 & $8.77 \pm 0.06 \mathrm{~b}$ & $22802.22 \pm 152.35 \mathrm{~b}$ & 852.72 & 3600 & $18349.28 \pm 152.35 \mathrm{~b}$ \\
N90 & $9.33 \pm 0.16 \mathrm{a}$ & $24266.67 \pm 409.82 \mathrm{a}$ & 784.41 & 3600 & $19882.26 \pm 409.81 \mathrm{a}$ \\
N80 & $8.22 \pm 0.03 \mathrm{c}$ & $21363.33 \pm 67.69 \mathrm{c}$ & 713.13 & $5.54 \pm 0.09 \mathrm{a}$ & 4600 \\
N70 & $7.90 \pm 0.13 \mathrm{c}$ & $20540.00 \pm 338.00 \mathrm{c}$ & 641.85 & 3600 & $17050.20 \pm 67.69 \mathrm{c}$ \\
\hline
\end{tabular}

Within treatment, means followed by different letters are significantly different according to LSD $(\mathrm{p} \leq 0.05)$.

\subsection{Soil Organic Matter Content}

As shown is Figure 1, the soil organic matter content of each treatment was ranked as $\mathrm{N} 80>\mathrm{N} 90>\mathrm{N} 70>\mathrm{N} 100>\mathrm{CK}>$ Basic soil (Basic soil samples collected before the experiment). The soil organic matter content of all treatments applied with organic fertilizer were significantly higher than Basic soil, increased by $15.87 \%, 14.35 \%, 13.91 \%, 12.83 \%$ and $11.74 \%$ respectively. Except for N80 and N90, no significant difference was found in the soil organic matter content among treatments applied with organic fertilizer. Interestingly, no significant difference was found between the CK without nitrogen fertilizer and other treatments. Importantly, data in Figure 1 showed a significant effect on the soil organic matter content when applying organic fertilizer. So the amount of nitrogen reduction had little effect on the soil organic matter content. This result may indicate that nitrogen fertilizer can significantly affect rice yield, but the increase of soil fertility is due to organic fertilizer.

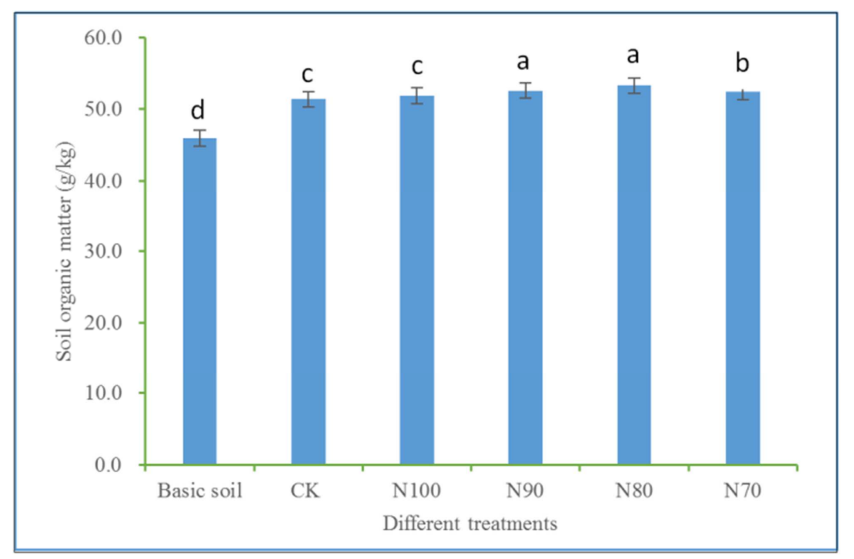

Figure 1. Effects of different treatments on soil organic matter content.

\section{Discussion}

\subsection{Effect on Yield and Yield Formation Factors}

Nitrogen is one of the main nutrients for rice growth and development, which has an important impact on the formation of rice yield and can significantly increase the panicle number plant-1 and the number of spikelets panicle ${ }^{-1}$, tillering is significantly influenced by $\mathrm{N}$ concentration [19]. But in this study, there was no significant difference in yield among the treatments applied with $\mathrm{N}$ fertilizer. The number of panicle did not increase continuously with the increase of N. Zhong reported that tillering is not only affected by nutrients, but also by space [24]. At present, many studies have shown that in the optimization of nitrogen treatment, the number of spikelets per panicle is more than that of farmers' fertilization practice management. [6, 15]. Combined application of organic and chemical fertilizers can increase the net photosynthetic rate of functional leaves and increase the accumulation of dry matter in the early stage of rice, thereby increasing rice yield $[10,16]$. Yi showed that compared with the local customary nitrogen fertilization, the rice yield in the first season of $20 \%$ nitrogen reduction did not significantly decrease, while the nitrogen agronomic efficiency and nitrogen partial factor productivity has increased [20]. In our study, N90 of $10 \% \mathrm{~N}$ fertilizer reduction got the yield as high as $9.33 \mathrm{t} / \mathrm{ha}$, which was significantly higher than CK and N100. Compared with $\mathrm{N} 100$, the output value, benefit, and benefit-cost ratio of N90 increased significantly by $6.38 \%$, $6.42 \%, 8.35 \%$, and $8.20 \%$, respectively.

\subsection{Effect on Nitrogen Efficiency in Rice}

The continuous increase of grain yield in China is based on the increasing input of nitrogen fertilizer. From the early 1990s, the problems of excessive nitrogen fertilizer input and low use efficiency began to surface in china's crop production [4]. Zhu found that the nitrogen use efficiency was as low as $20 \%-35 \%$, chemical fertilizer combined with organic fertilizer can not only reduce the input of chemical fertilizer, but also promote the transport of nitrogen in vegetative organs and increase the rice yield [25]. $\mathrm{Li}$ indicated that the application of organic fertilizer can promote the fixation of nitrogen microbes and increase nitrogen use efficiency [7]. Zhang showed that applying nitrogen with $140 \mathrm{~kg} / \mathrm{ha}$, the economic benefits of rice production and nitrogen use efficiency were the highest, the nitrogen agronomic efficiency and nitrogen partial factor productivity were 11.5 and $63.2 \mathrm{~kg} / \mathrm{kg}$, respectively [23]. Our study showed that combined application of organic fertilizer, $10 \%$ reduction in nitrogen significantly improved the nitrogen agronomic efficiency and the nitrogen recovery efficiency, which were as high as $19.78 \%$ and $34.76 \%$. And the treatments of reducing nitrogen by $10 \%, 20 \%$ and $30 \%$ significantly improved the nitrogen physiological efficiency and nitrogen partial factor productivity, significant 
differences were observed compared with N100.

\subsection{Effect on Soil Organic Matter Content}

The soil organic matter content can directly reflect the level of the soil fertility. Organic fertilizer has an extremely significant role in increasing soil nutrition and improving soil structure [17]. Organic matter directly affects the growth and yield of crops by providing nutrients, and indirectly improves the root environment and stimulates plant growth by changing the physical properties of the soil (such as the stability and porosity of aggregates), thereby indirectly affecting the growth and yield of crops [2].

Combined application of organic fertilizer and chemical fertilizer can not only ensure adequate available nutrients but also reduce nutrient loss and improve fertilizer use efficiency, thereby significantly increasing rice yield. Our results showed that the soil organic matter content of the treatments applied with organic fertilizer was significantly higher than that of the basic soil (sampled before the test). Except for N80, no significant difference in soil organic matter content was found among all the treatments, which indicated that while applying the same amount of organic fertilizer, the amount of nitrogen reduction has little effect on the soil organic matter content.

\section{Conclusion}

Thus from the present investigation it may be concluded that combined use of organic fertilizer at $4500 \mathrm{~kg} / \mathrm{ha}$ and nitrogen reduction by $10 \%$ (N90) resulted in the significant improvement in yield and benefit-cost ratio in rice production and increase of nitrogen use efficiency. It was also observed that combined use of organic fertilizer at $4500 \mathrm{~kg} / \mathrm{ha}$ and nitrogen reduction by $10 \%$ (N90) led to improvement in soil organic matter content, the amount of nitrogen reduction has little effect on the soil organic matter content while applying the same amount of organic fertilizer. So combined use of organic fertilizer at $4500 \mathrm{~kg} / \mathrm{ha}$ and nitrogen reduction by $10 \%$ (N90) may be practiced in red soil regions of the South China to improve soil physical environment and enhance soil organic matter and for achieving higher yield through efficient utilization of nitrogen in rice.

\section{Acknowledgements}

The authors thank Jiangxi Province Key Lab for Digital Land (DLLJ201807) and the Science and Technology Plan Project of Jiangxi Provincial Department (GJJ170448) for financial supporting the senior author.

\section{References}

[1] Bandyopadhyay K. K., Misra A. K., Ghosh P. K., Hati K. M., 2010. Effect of integrated use of farmyard manure and chemical fertilizers on soil physical properties and productivity of soybean. Soil and Tillage Research, 110: 115-125.
[2] Darwish, O. H., Persaud, N., Martens, D. C., 1995. Effect of long term application of animal manure on physical properties of three soils. Plant Soil 176, 289-295.

[3] He X., Rong X. M., Xie Y., Shi D. J., Tang L., 2017. Effects of fertilization reduction and organic fertilizer replacement on rice yield and nutrient utilization. Hunan Agricultural Science, 3: 31-34.

[4] Ju X. T., Xing G. X., Chen X. P., Zhang S. L., Zhang L. J., Liu X. J., Cui Z. L., Yin B., Christie P., Zhu Z. L., Zhang F. S., 2009. Reducing environmental risk by improving $N$ management in intensive Chinese agricultural systems. Proceedings of the national academy of sciences of the United States of America, 106 (9): 3041-3046.

[5] Ladha J. K., Pathak H., Krupnik T. J., Six J., Kessel C., 2005. Efficiency of fertilizer nitrogen in cereal production: Retrospects and prospects. Advances in Agronomy, 87: 86-156.

[6] Li, D. Q., Tang, Q. Y., Zhang, Y. B., Qin, J. Q., Li, H., Chen, L., Yang, S. H., Zou, Y. B., Peng, S. B., 2012. Effect of nitrogen regimes on grain yield, nitrogen utilization, radiation use efficiency, and sheath blight disease intensity in super hybrid rice. J. Integr. Agric. 11, 134-143.

[7] Li S. Q., Li S. X., 2001. Effects of organic materials on maintaining soil microbial biomass nitrogen. Acta ecologica sinica, 21 (1): 136-142.

[8] Ling Q. H., Zhang H. C., Dai Q. G., Ding Y. F., Li L., Su Z. F., $\mathrm{Xu}$ M., Que J. H., Wang S. H., 2005. Study on precise and quantitative $\mathrm{N}$ application in rice. Scientia Agricultura Sinica, 38 (12): 2457-2467.

[9] Liu H. J., Zheng J. C., Guo Z., Chen L. G., Zhang Y. F., Wang X., 2016. Effects of reduced nitrogen application on nitrogen uptake and use efficiency of rice in Taihu area. Chinese Journal of Ecology, 35 (11): 2960-2965.

[10] Liu L. J., Wang K. J., Bian J. L., Xiong Y. W., Chen L., Wang Z. Q., Yang J. C., 2014. Differences in yield response to nitrogen fertilizer among rice cultivars and their relationship with root morphology and physiology. Acta Agronomica Sinica, 40 (11): 1999-2007.

[11] Liu M. Q., Hu F., Chen X. Y., Huang Q. R., Jiao J. G., Zhang B., Li H. X., 2009. Organic amendments with reduced chemical fertilizer promote soil microbial development and nutrient availability in a subtropical paddy field: The influence of quantity, type and application time of organic amendments. Applied Soil Ecology, 42: 166-175.

[12] Meng Y., Wang Q., Huang. Q. W., Yang X. M., Xu Y. C., Shen Q. R., 2008. Effects of combined application of pig manure compost and inorganic fertilizers on rice grains and nitrogen efficiency. Journal of Ecology and Rural Environment, 24 (1): 68-71.

[13] Peng S. B., Huang J. L., Zhong X. H., Yang J. C., Wang G. H., Zou Y. B., Zhang F. S., Zhu Q. S., Roland B., Christian W., 2002. Research Strategy in Improving Fertilizer-nitrogen Use Efficiency of Irrigated Rice in China. Scientia Agricultura Sinica., 35 (9), 1095-1103.

[14] Peng S. B., Buresh R. J., Huang J. L., Yang J. C., Zou Y. B., Zhong X. H., Wang G. H., Zhang F. S., 2006. Strategies for overcoming low agronomic nitrogen use efficiency in imigated rice systems in China. Field Crops Research, 96: 37-47. 
[15] Peng, X. L., Liu, Y. Y., Luo, S. G., Fan, L. C., Song, T. X., Guo, Y. W., 2007. Effects of site-specific nitrogen management on yield and dry matter accumulation of rice from cold areas of northeastern china. Agric. Sci. China 6, 715-723.

[16] Ru Y. X., Cui X. W., Fan H. S., Long S. P., Peng F. Y., 2015. Effects of combined application of manure and chemical fertilizer on the growth of rice and soil biological characters in paddy soils. Chinese soil and fertilizer, 5: 50-55.

[17] Tang J. W., Lin Z. A., Xu J. X., Qi J., Wang Y. H., 2006. Effect of organic manure and chemical fertilizer on soil nutrient. China soil and fertilizer, 3: 44-47.

[18] Tesfaye S. G., Ismal M. R., Kausar H., Marziah M., Ramlan M. F., 2013. Plant water relations, crop yield and quality of Arabica Coffee as affected by supplemental deficit irrigation. International J. Agr. Biol., 15 (4), 665-672.

[19] Wang Y. J., Ge M. J., Yan X. T., Wei H. Y., Zhang H. C., Dai Q. G., Huo Z. Y., Xu K., 2014. Effects of light, nitrogen and their interaction on grain yield and matter production characteristics of Japonica super rice. Acta Agronomica Sinica, 40 (1): 154-165.

[20] Yi Q., Zhang X. Z., He P., Yang L., Xiong G. Y., 2010. Effects of reducing $\mathrm{N}$ application on crop $\mathrm{N}$ uptake, utilization, and soil $\mathrm{N}$ balance in rice-wheat rotation system. Plant nutrition and fertilizer science, 16 (5): 1069-1077.

[21] Zeng X. J., Liu D. K., 2005. Influence organic-inorganic-mixed fertilizers application on yield and quality of vegetable. Journal of Hunan Agricultural University, 31 (4): 402-404.

[22] Zhang F. S., Wang J. Q., Zhang W. F., Cui Z. L., Ma W. Q., Chen X. P., Jiang R. F., 2008. Nutrient use efficiencies of major cereal crops in China and measures for improvement. Acta Pedologica Sinica, 45 (5): 915-924.

[23] Zhang X. Z., Y Q., Zhu P., He P., Yang L., Fan X. P., Xiong G. Y., 2011. Agronomic responses to nitrogen application and nitrogen utilization in rice fields. Plant nutrition and fertilizer science, 17 (4): 782-788.

[24] Zhong X., Peng S., Sheehy, J. E., Visperas, R. M., Liu, H., 2002. Relationship between tillering and leaf area index: quantifying critical leaf area index for tillering inrice. J. Agric. Sci. 138, 269-279.

[25] Zhu Z. L., Fan X. J., Sun Y. H., Wang D. J., 2004. Nitrogen cycling and its environmental effects of rice in paddy soil in Taihu Lake area. Crop research, 4: 187-191. 